\title{
Sagittal Cresting in the South African Australopithecines ${ }^{1}$
}

\author{
MILFORD H. WOLPOFF \\ Department of Anthropology, University of Michigan, Ann Arbor, \\ Michigan, 48104
}

KEY WORDS Australopithecine $\cdot$ Sagittal cresting.

\begin{abstract}
The evidence for sagittal cresting, and more generally the position of the temporal lines is reviewed in the South African australopithecine sample. The position of the lines is dependent on both the allometric relation of the masticatory apparatus to cranial size and on individual variation. In the Swartkrans specimens, with generally bigger body size, the influence of allometry predominates, actually overshadowing the influence of individual variation. At Sterkfontein and Makapansgat with generally smaller body size and a resulting smaller allometric ratio, individual variation has a greater influence. Of the eleven adult South African specimens, the four largest are crested. The one smaller crested specimen comes from Sterkfontein. The crested Makapan specimen is intermediate in size. The pattern of australopithecine cresting is somewhat different from other hominoids, and is part of a total morphological pattern suggesting adaptation to a diet requiring powerful crushing during mastication.
\end{abstract}

Sagittal crests in hominoids are compound crests caused by the pull of both temporalis muscles when they meet at the midline of the cranium. Functionally, the crest provides additional area for the attachment of $m$. temporalis when the area provided by the external cranial surface is insufficient.

Formation of a sagittal crest is under the direct control of the superior fascial attachment of $m$. temporalis, and does not necessarily depend on the meeting of two simple temporal crests. If the two superior fascial attachments of $m$. temporalis meet at the midline, the fasciae run together to the underlying bone, and a two layered fibrous septum between the muscles is formed (Scott, '54). The resulting osteogenic activity leads to ossification extending into this septum, producing a sagittal crest. Ossification proceeds along the union of the fascia and the outer layer of the periosteum, and the resulting crest consists of two laminae which later fuse together.

The cresting process is the same for all hominoids. However, the position of the crest when it first forms, and its anterior and posterior extension, depend on the relative development of the anterior and posterior fibers of $m$. temporalis.

Zuckerman ('66) has shown that the fi- bres of $m$. temporalis first come together posteriorly in many primates, and that the sagittal crest first forms in the posterior region, often in conjunction with a compound temporal/nuchal crest. This does not seem to be true in australopithecines where the temporal lines first meet at bregma or anterior to it, and the compound or intermediate temporal/nuchal crest, when it occurs, is only along the lateral third of the nuchal crest (Robinson, '58; Tobias, '67). This indicates a relatively greater development of the anterior fibers of $m$. temporalis. This anterior development also occurs in $H$. sapiens where the closest approach of the temporal lines in crania with high lines occurs in the region of bregma (Riesenfeld, '55).

There are two variables which systematically influence the relation of temporalis size, and area available for attachment The first is the allometric relation between the size of the masticatory apparatus and the size of the cranium. As Huxley ('32) noted for baboons, increase of body size in the same, or even very similar, species leads to far greater differences in the masticatory apparatus than in the size of the cranium, resulting in a disproportionate

1 This research was supported by NSF grant GS-33035. 
increase in the jaws and supporting masculature. The same relation can be seen in comparing chimpanzees and gorillas. The summed posterior tooth area for gorillas is more than double that of chimpanzees while the average cranial capacity is less than double. The effect of this allometric component is to decrease the relative area available for the attachment of $m$. temporalis with increasing body size. The second variable influencing the relative attachment area available on the cranium is individual variation resulting from both genetic and environmental influences, with the latter especially acting on the size and robustness of $m$. temporalis. These variables are not mutually exclusive.

The purpose of this paper is to review the data concerned with the position of the temporal line and sagittal cresting in the large South African australopithecine sample now available for study. The point of this review is twofold: first to determine the interaction of the allometry and individual variation components in temporal line height, and compare these with other primate models; and second to reconstruct the function of $m$. temporalis suggested by the australopithecine cresting pattern.

The terminology used here follows that suggested by Robinson ('58). A simple crest, or ridge, is a raised area or elevated line marking the periphery of a muscle not closely bordered by another muscle. Thus, $m$. temporalis forms a crest where it borders the temporal fossa and for the extent that it parallels the superior orbital margin, but as it travels posteriorly it becomes an unelevated line. A compound crest, such as the sagittal crest, occurs at the interface of two muscle masses. Specimens are divided into gracile and robust samples based on published taxonomic statements. The gracile sample consists of specimens from Sterkfontein (STS) and Makapan (MLD), and the robust sample consists of specimens from Swartkrans (SK). I have made all observations and measurements used in this study on the original specimens.

\section{THE SPECIMENS}

$M L D$ 1. The question of cresting in this specimen depends' on the true position of lambda. According to Dart ("48), the temporal lines come within $5 \mathrm{~mm}$ of each other at lambda. This is actually closer together than the temporal lines at lambda of $\mathrm{OH} 5$ and ER 406 (Tobias, '67; Leakey, Mungai, and Walker, '71), making it likely that MLD 1, too, had a sagittal crest. However, there are at least 12 distinct Wormian bones in the vicinity of lambda on both the lambdoidal and sagittal sutures. The lambdoidal suture is clear of Wormian bones in the vicinity of asterion and for about 30 mm medially. For lambda, Dart picked the point furthest posterior on the sagittal suture anterior to the Wormian bone development. Dart's definition makes the ratio of lambda-inion to inion-opisthion chords 55/37, an unusually high ratio for an australopithecine. This point cannot possibly be lambda, as it would put the inferior limb of the parietal branch of the middle meningeal artery on the occipital. The lambdoidal suture can be clearly traced to the sagittal suture internally, bordering the fossa for the occipital pole of the cerebrum. Consequently, lambda can be un ambiguously defined internally, and the corresponding point can be defined on the external surface. I believe this is the most appropriate definition of lambda. No sutures cross at this external point, $18.5 \mathrm{~mm}$ posterior to the point defined by Dart. Using it, the chord ratio of lambda-inion to inionopisthion is about 39/37, much more like the other australopithecine specimens (Tobias, '67; 13). The parietals extend for 34 $\mathrm{mm}$ anterior to lambda. At the most anterior point, the temporal lines are $5 \mathrm{~mm}$ apart. At $34 \mathrm{~mm}$ anterior to lambda on $\mathrm{OH} 5$, the lines have already met, and on ER 406, the lines have just come together. These are the only crested specimens that show the morphology of this region. However, the distance between the temporal lines at lambda is known for a number of specimens. The $35 \mathrm{~mm}$ value for MLD 1 is greater than both $\mathrm{OH} 5$ and ER 406. It is far less than the distance for the uncrested specimens (table 1), and less than the value which can be estimated for STS 71 where the temporal lines meet at bregma. Since on the most anterior portion of MLD 1 the temporal lines are only $5 \mathrm{~mm}$ apart and still converging, and because sagittal cresting in the australopithecines is anterior, I concur with Robinson's judgment (58: 413-416) that the specimen probably had a sagittal crest.

$M L D$ 10. The specimen is a pair of 
TABLE 1

Temporal line position and other comparable cranial measures of the South African australopithecines

\begin{tabular}{|c|c|c|c|c|c|c|c|c|c|}
\hline & $\begin{array}{l}\text { Minimum ap- } \\
\text { proach tem- } \\
\text { poral lines }\end{array}$ & $\begin{array}{l}\text { Stephan- } \\
\text { ion breg- } \\
\text { ma arc }\end{array}$ & $\begin{array}{l}\text { Distance } \\
\text { between } \\
\text { temporal } \\
\text { lines at } \\
\text { lambda }\end{array}$ & $\begin{array}{l}\text { Sagittal } \\
\text { crest to } \\
\text { bregma }\end{array}$ & $\begin{array}{l}\text { Biaster- } \\
\text { jonic } \\
\text { breadth }\end{array}$ & $\begin{array}{c}\text { Gla- } \\
\text { bella } \\
\text { bregma } \\
\text { arc }\end{array}$ & $\begin{array}{c}\text { Glat } \\
\text { bella } \\
\text { bregma } \\
\text { chord }\end{array}$ & $\begin{array}{l}\text { Bregma } \\
\text { lambda } \\
\text { arc }\end{array}$ & $\begin{array}{l}\text { Lambda } \\
\text { opisthion } \\
\text { arc }\end{array}$ \\
\hline & $m m$ & $m m$ & $m m$ & $m m$ & $m m$ & $m m$ & $m m$ & $m m$ & $\begin{array}{c}m m \\
79\end{array}$ \\
\hline MLD 1 & 0? & & 35 & & & & & & \\
\hline MLD 10 & 20 & & 471 & & & & & & \\
\hline MLD $37 / 38$ & 70 & 35 & 48 & & 80 & & & 87 & 71 \\
\hline STS 5 & 40 & 22 & 51 & & 72 & 80 & 77 & 92 & 72 \\
\hline STS 25 & 25 & 14 & & & 73 & & & 81 & \\
\hline STS 71 & 0 & 0 & & & $\sim 77$ & 75 & 69 & 85 & 73 \\
\hline SK 27 & 74 & 40 & & & 100 & & & 71 & \\
\hline SK 46 & 0 & 0 & & 24 & & & $>72^{2}$ & 106 & \\
\hline SK 47 & & & & & 78 & & & & \\
\hline SK 48 & 0 & 0 & & 29 & & 78 & 75 & & \\
\hline SK 49 & 0 & 0 & & 26 & & & & & \\
\hline SK 54 & 69 & 35 & 105 & & & & 70 & 86 & \\
\hline SK $80 / 847$ & 481 & $33^{3}$ & & & $70^{1}$ & & & $85^{3}$ & \\
\hline
\end{tabular}

I Estimated by doubling the midline distance.

2 Position of glabelia reconstructed using SK 48 as a model.

3 Bregma determined by convergence of the sagittal and coronal sutures, both present several millimeters from the point. The determination was unambiguous.

fused parietals and a fragment of occipital extending from a point somewhat posterior to lambda anteriorly for $60 \mathrm{~mm}$ in front of lambda. There is no trace of the coronal suture on the anterior edge. At the most anteriorly preserved point on the sagittal suture, the temporal lines are $20 \mathrm{~mm}$ apart. They are asymmetric, the left being $9 \mathrm{~mm}$ from the suture and the right $13 \mathrm{~mm}$. Internally, the sagittal suture is closed, although not fused. It is unlikely that the specimen had a sagittal crest, as it was apparently an aged adult at the time of its death.

$M L D$ 37/38. The specimen is an almost complete calvaria without face (Dart, '62). A transverse break continues a little behind the coronal suture on the left, crosses it $12.5 \mathrm{~mm}$ left of bregma, and continues anteriorly and medially. The temporal lines are clearly visible; the specimen did not have a sagittal crest. Eruption of $\mathrm{M}^{3}$ indicates that the specimen is adult, although it appears that the right tooth was reduced and newly erupted because it is only slightly worn while the left shows considerable wear. I do not believe, as Dart ('62) sug. gests, that the right tooth is a supernumerary $\mathrm{M}^{4}$ because of the symmetry of the palate. The spheno-occipital synchonchrosis is closed but still clearly visible, corresponding to an age of 24-28 based on modern suture closure critera. My comparisons of suture closure and dental ageing indicate that suture closure in the South African sample follows the same general pattern which occurs in modern man.

STS 5. The specimen is a complete, edentulous cranium (Broom, Robinson, and Schepers, '50). Although most of the outer bone table is lost, the temporal lines are visible. There is no sagittal crest. The specimen is adult, and judging by endocranial suture closure at least in her (?) 30's.

STS 17. The specimen (fig. 3) consists of a frontofacial fragment with a full palate (Broom, et al., '50). The face extends past the midline at the base of the nasal aperture, although it does not reach the midline superior to this area. An associated occipital fragment seems to include lambda. It is so crushed and fragmented that no surface detail can be observed. Using the midline defined by the palate and nasal aperture, the position of the midline for the remaining face was reconstructed. The superior border of the orbit is broken at a point $10 \mathrm{~mm}$ lateral to the midline. At this point the temporal crest travels parallel with the superior orbital margin for its entire preserved extent, and it only begins to turn posteriorly at the position of the medial break. The closest approach of the crest to the superior orbital margin is $8.3 \mathrm{~mm}$. A concave flattening of the supraglabellar 
area, such as that described by Tobias for $\mathrm{OH} 5$ as a frontal trigone ( $67 ; 104)$, is preserved for $12.5 \mathrm{~mm}$ lateral to the break, which is $10 \mathrm{~mm}$ from the midline. This general area may be compared with other specimens both without (STS 5, ER 732) and with (SK 48, ER 406) crests. In STS 5, the temporal line begins a gentle posteromedial arc as it leaves the superior border of the temporal fossa (temporal notch). The line never is as close to the midline as $10 \mathrm{~mm}$. ER 732, an East African specimen without a sagittal crest (Leakey, Mungai, and Walker, '72), has a frontal trigone, indicating that this morphology does not necessarily indicate sagittal cresting. In this specimen, the temporal line begins to turn posteriorly $34 \mathrm{~mm}$ from the midline, some $7 \mathrm{~mm}$ after it has left the temporal fossa. The line does not come within $10 \mathrm{~mm}$ of the midline on the frontal. The frontal trigone extends $21 \mathrm{~mm}$ from the midline, and thus is about the size of the trigone area in STS 17. The morphology of SK 48 much more closely approximates the condition in STS 17. In fact, the temporal crest remains more anterior and medial in the latter. Ten millimeters from the midline, the temporal line is already midway in its posterior turn, and is some $28 \mathrm{~mm}$ behind the superior orbital margin. The position morphologically equivalent to $10 \mathrm{~mm}$ from the midline in STS 17 is $23 \mathrm{~mm}$ from the midline in SK 48 , where the line first begins its posterior turn. At this point it is $17 \mathrm{~mm}$ behind the superior orbital margin. Similarly in ER 406 the line is almost completely turned posteriorly at a point $10 \mathrm{~mm}$ from the midline, and is $31 \mathrm{~mm}$ behind the superior orbital rim. It begins its posterior turn 27 $\mathrm{mm}$ from the midline, when it is $14.4 \mathrm{~mm}$ behind the orbit. Even if the midpoint estimate for STS 17 is off by $100 \%$ it still closely matches the morphology for these two crested specimens.

There are two points to be considered. First, sagittal cresting, or closest approach of the temporal lines, in australopithecines is uniformly anterior, occurring at or anterior to bregma. Second, the temporal crest in STS 17 parallels the orbit and the line begins its posterior turn in a more medial position for STS 17 than is the case for the two crested specimens discussed, and far more medially than in the two uncrested specimens and STS 71. Although the sagittal area of the frontal and parietals of STS 17 is missing, what possible course could the lines take if they did not form an anterior sagittal crest? The alternative would suggest that the specimen had anterior fibers of $m$. temporalis better developed than the robust specimens discussed, and almost no posterior development at all. In my view, it is probable that STS 17 had a sagittal crest. $M^{3}$ is fully in occlusion and worn, indicating the specimen is adult.

STS 25. The specimen is a calvaria and cranial base, extending from the occipital to the supraorbital region. The specimen is lacking much surface detail, and parts of the base are still enclosed in matrix. The left temporal appears crushed somewhat laterally. Although much of the outer bone table is gone, the position of the temporal lines can be determined. There is no sagittal crest.

STS 71. The specimen (fig. 2) is an almost complete cranium with much of the left side broken away. The base of the right parietal is crushed downwards and somewhat laterally over the temporal. Broom (Broom, et al., '50) thought the back of the skull was crushed downwards and somewhat anteriorly. I do not believe this is true. There is no evidence of overlapping bone in the sagittal plane which would result from anterior crushing of the occipital region. The cranial bone surface is complete and continuous from glabella to opisthion. Thus, if the occipital region were crushed anteriorly, it must also be flexed in a downwards direction. This is unlikely because the nuchal line, as preserved, is several millimeters above the Frankfort Horizontal. While there is no sagittal crest, the temporal lines meet for a millimeter in the region of bregma. At the midpoint of the orbit the line is $20 \mathrm{~mm}$ behind the superior orbital margin, and is already angling about 45 degrees away from the margin. The right line continues to the rear of the cranium where it meets the nuchal line to form an apparent, although not raised, compound crest area at the posterior position of the mastoid process, $39 \mathrm{~mm}$ behind porion. $M^{3}$ is fully in occlusion and worn.

STS 1006. The specimen (figs $4 \mathrm{a}, \mathrm{b}$ ) is a new juvenile frontofacial fragment discovered in 1972, consisting of most of the right portion of a face with a complete 
nasal aperture, and part of the frontal behind the right orbit. Much of the face is lost anterior to a line perpendicular to the base of the orbit, and the alveolar margin is broken away exposing roots above the bifurcation. The posterior roots, present on both sides, measure $13 \mathrm{~mm} \times 12.6 \mathrm{~mm}$ on the right and probably belong to $\mathrm{M}^{1}$. On the left side there is a palatine foramen just level with this root. The root anterior to this best matches the posterior root for $\mathrm{dM}^{2}$, rather than $\mathrm{P}^{4}$. Thus, the specimen is likely between the age of Taung and the age of SK 27 (8-10). It makes an interesting comparison with these two specimens, as 1006 is quite unlike Taung and rather closely matches SK 27. The supraorbital torus is well developed and set off from the frontal bone by a supraorbital sulcus. The temporal line is medial on the frontal bone. It does not travel parallel with the superior orbital margin but rather angles medially and posteriorly from the temporal notch in a smooth arc. At the midpoint of the orbit the temporal line is $25.5 \mathrm{~mm}$ posterior to the superior margin and $27 \mathrm{~mm}$ from the midline. In all, this region is much like SK 27.

SK 27. The specimen is a very crushed cranium (Broom and Robinson, '52). Most of the distortion is flattening, so that the highest point on the cranium is about 75 mm above the lowest. $\mathrm{M}^{2}$ is unerupted and rootless. The left $\mathrm{I}^{2}$ is in occlusion. The temporal lines are visible and not prominent. On the left side, the line meets the supramastoid crest just behind the mastoid area, some $25 \mathrm{~mm}$ anterior to asterion. The line leaves the temporal notch and immediately arcs medially and posteriorly. The superior cranial surface is distorted, but for the regions discussed there is no overlapping of bone or matrix filled cracks. Accurate chords cannot be taken but arcs are possible. The arc from the temporal line to bregma is $39 \mathrm{~mm}$, which is about half the distance from fmo (the fronto-zygomatic suture at the orbital border) to the midline. From the lateral orbital rim, the most medial position of the line is $24 \mathrm{~mm}$. The age of SK 27 is probably $8-10$ years, based on tooth eruption and wear.

SK 46. The specimen (fig. 1) consists of most of a somewhat distorted cranium (Broom and Robinson, '52). The glabellar region is missing, but the cranial surface is otherwise complete to lambda. SK 46 is one of the two South African robust australopithecine adults with a fairly complete parietal. The parietal, especially in the posterior portion, is crushed downwards and medially, so that the region of porion is angled at $45^{\circ}$ to and is $40 \mathrm{~mm}$ from the sagittal plane. The superior cranial surface is continuous to lambda, and arcs taken on it should be accurate. A minimum reconstruction of glabella was made by following the line of the supraorbital torus to the midline. This assumes no glabellar prominence such as occurs on SK 48. If this region matches SK 48 , glabella is further anterior. The position of the coronal suture and bregma was identified using a binocular microscope. As reconstructed, the glabella-bregma chord is $72 \mathrm{~mm}$. There is a well developed sagittal crest, beginning 24 $\mathrm{mm}$ in front of bregma and extending for about $45 \mathrm{~mm}$ posterior to bregma until it is broken off (Robinson, '58). $\mathrm{M}^{3}$ is in occlusion and well worn.

SK 47. The specimen is a very crushed juvenile cranium (Broom and Robinson, '52). The nuchal torus can be traced from the mastoid process to inion. The temporal line is well above it. $\mathrm{M}^{2}$ shows slight wear on the mesial cusps and $\mathrm{P}^{4}$ is barely beyond the alveolar margin. The high temporal line seen on the occipital portion of this juvenile specimen makes it unlikely, although not impossible, that it had a sagittal crest. Tooth wear and eruption indicate an age of 13-14.

$S K 48$. The specimen is one of the more complete crania from Swartkrans, although there is much crushing and distortion (Broom and Robinson, '52). The cranial surface is lost behind bregma, and the posterior portion of the skull is mostly missing. The anterior distortion of the posterior region is reflected in the base where the foramen magnum is between the pterygoid processes. A sagittal crest begins anterior to bregma, identified with the use of a binocular microscope. At the midpoint of the orbit, the temporal crests are still parallel with the superior orbital margin. This is the usual case in robust specimens such as $\mathrm{OH} 5, \mathrm{ER} 406, \mathrm{SK} 79$, and SK $52 . \mathrm{M}^{3}$ is erupted and worn.

$S K 49$. This very crushed and fragmented specimen was discussed in detail by Robinson (58). A sagittal crest is present. 


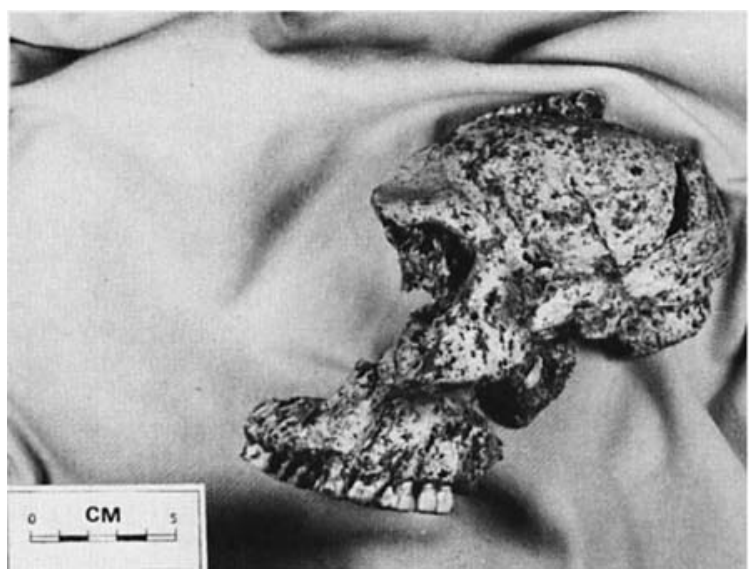

Fig. 1 SK (Swartkrans) 46. The temporal ridge parallels the orbit, bordering laterally the frontal trigone, and then smoothly sweeps posteriorly as a line, converging with the opposite line to form a sagittal crest.

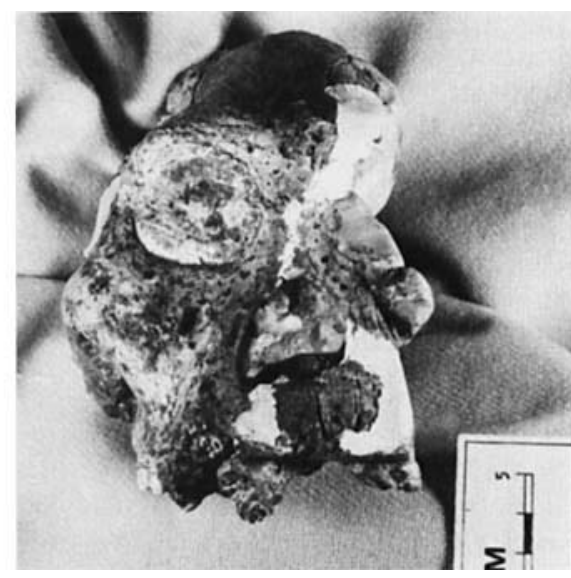

Fig. 2 STS (Sterkfontein) 71. The temporal line arcs posteriomedially as it leaves the temporal notch (superior border of the temporal fossa), and meets the opposite line at bregma. There is neither a sagittal

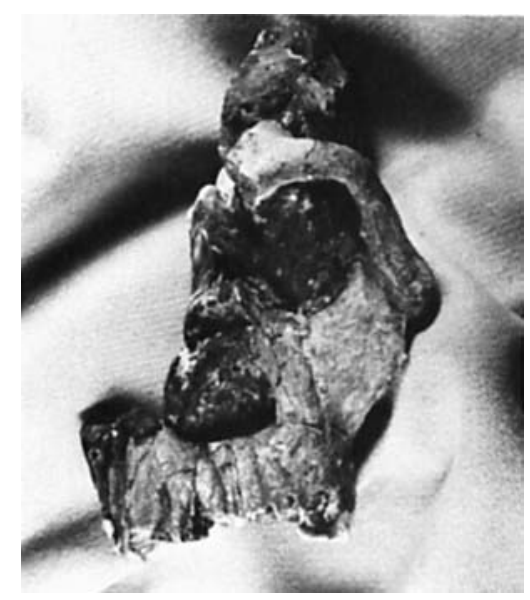

Fig. 3 STS 17. The temporal ridge parallels the orbit to a more medial position than occurs in SK 46, and then arcs posteriorly with a strong medial angle to the point where the cranium is broken, about $10 \mathrm{~mm}$ from the midline. A frontal trigone is present, and it is likely that the specimen was crested. Same scale as figure 2 .
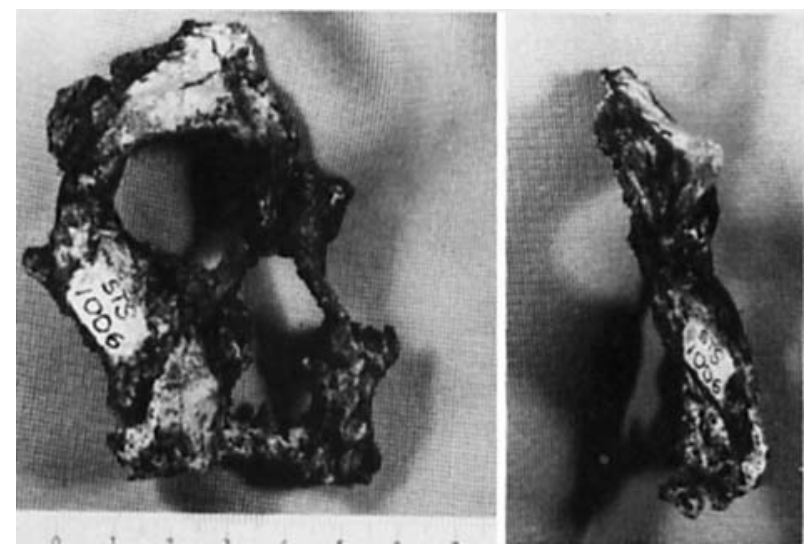

Fig. 4 STS $1006.4 \mathrm{a}$ (left) is anterior and $4 \mathrm{~b}$ (right) lateral. The temporal line of this juvenile specimen arcs posteriomedially from the temporal notch, reaching a position on the preserved bone more medial than that of STS 5 . There is a strong supraorbital torus development and a supraorbital sulcus.
The crest begins about $26 \mathrm{~mm}$ anterior to bregma. Ten millimeters anterior to lambda the crest is absent, and no trace of the temporal lines can be seen. The mesial cusps of $\mathrm{M}^{3}$ are worn, indicating that the specimen is adult.

$S K$ 54. The specimen is a juvenile cranium, complete from nasion to inion, with extensive plastic distortion (Brain, '70). The skull is folded along the coronal suture. Both parietals are present to the temporal border. The supraorbital torus is almost undeveloped but set off from the frontal by a supraorbital sulcus. The temporal line, while not particularly medial, is well developed and prominent. The line arcs pos- 
teriorly and medially from the temporal notch. Just behind the notch it is $32 \mathrm{~mm}$ from the midline of the frontal. While it is not possible to age the specimen precisely, the open sutures and lack of supraorbital development indicate it was adolescent if not juvenile. No sagittal crest occurs.

SK 80/847. The specimen is a composite of SK 80 and 847 consisting of the face, part of the frontal lateral to the midline, and most of the temporal and sphenoid. The true position of temporal line on the frontofacial fragment is difficult to establish because of a groove which angles quite medially from the superior border of the temporal fossa, or the temporal notch. A binocular microscope was used to determine the position of the less well developed line. The line leaves the temporal notch in a gentle arc. At its furthest posterior position on the fragment it is $18 \mathrm{~mm}$ from the midline and $27.8 \mathrm{~mm}$ behind the superior orbital margin. At this point it is angled about 90 degrees to the orbital margin, although since the margin angles strongly anteriorly and medially, the line is still far from parallel to the sagittal plane. Eighteen millimeters from the midline in STS 5, the temporal line is already parallel with the sagittal plane. Originally I suggested the specimen might have had a sagittal crest (Wolpoff, '71a) because Tobias' published measurements of supraorbital torus length, taken "to the temporal crest or line" (67: 104) suggested to me that the line closely paralleled the superior orbital margin. Examination of the specimen revealed that this is not the case, and the lateral position of the line indicates that a crest is unlikely. Heavy wear on the third molar and fusion of the stylovaginal process of the temporal suggest an advanced age for the specimen, so lack of cresting cannot be due to age.

SK $847 e$. This is a piece of left parietal including sagittal and lambdoidal suture found in the same block of breccia as the frontofacial fragment (without the maxilla SK 80 ) in close proximity to it. Proximity in the Transvaal caves does not necessarily indicate that fragments belong to the same specimen. However, I believe it likely that SK $847 \mathrm{e}$ goes with the frontofacial and temporal portions of the composite cranium. Although Clarke, Howell, and Brain ('70) did not find it, a small section of coronal
TABLE 2

Size comparisons of $S K 80 / 847$, the composite Swartkrans cranium, with other South African australopithecines

\begin{tabular}{lccc}
\hline & $\begin{array}{c}\text { Mastoidale } \\
\text { to (mm) } \\
\text { prosthion }\end{array}$ & $\begin{array}{c}\text { Auricular } \\
\text { point to } \\
\text { glabella }\end{array}$ & $\begin{array}{c}\text { Auricular } \\
\text { point } \\
\text { to fmd }\end{array}$ \\
\hline SK 80/847 & 126 & $m m$ & $m m$ \\
SK 52 1 & 135 & 101 & 65 \\
SK 48 & & 110 & 73 \\
SK 46 & $>148$ & $116^{2}$ & 81 \\
STS 5 & 150 & 110 & 79 \\
STS 71 & $>130$ & 94 & 68 \\
\hline
\end{tabular}

1 These values are minimum since $\mathrm{M}^{3}$ is still in its crypt.

2 Glabella is reconstructed following the morphology of SK 48

${ }^{3}$ Frontomalare orbitale, the orbital end of the frontozygomatic suture.

suture is present several millimeters from the midline. By extending this suture to the midline, and extending the sagittal suture forward, the position of bregma can be accurately determined. The resulting bregmalambda chord cannot be greater than 75 $\mathrm{mm}$, and is probably several millimeters less. This makes it a very small bone compared with any of the other South African specimens. The bregma-lambda arc is 85 $\mathrm{mm}$, slightly less than the value for SK 54 , although greater than SK 27. The only adult Swartkrans specimen for which this arc can be taken, SK 46 , has a value of $106 \mathrm{~mm}$. The corresponding arc on the SK 1585 endocast, with a cranial capacity of $530 \mathrm{cc}$ (Holloway, '72) is $91 \mathrm{~mm}$. The arc would be greater on the external cranial surface. In all, SK 847e appears to be a very small parietal compared with the other Swartkrans specimens. Some comparisons can be made between the size of the composite cranium and other adult Swartkrans specimens. Tables 1 and 2 indicate that where such comparisons are possible, the composite skull is much smaller. The fact that the parietal and the cranium are separately much smaller when compared to the other Swartkrans specimens, plus their close proximity, make it likely that they belong to the same individual. The position of the temporal line on the resulting composite shows that no sagittal crest occurred. Alternatively, if the parietals and composite cranium represent two separate individuals, then both lack the sagittal crest. These would be the two smallest adult specimens at Swartkrans. 


\section{DISCUSSION}

The formation of a sagittal crest, and more generally the height of the temporal lines, is dependent upon two factors: the size of $m$. temporalis, and the amount of area available for its attachment on the cranium. These factors seem to covary in gorillas, following the expected relation that brain size increases less rapidly than the masticatory apparatus with increasing body size. Thus in a sample of over 200 specimens in the Hamann-Todd collection, I have observed that the bigger specimens, regardless of sex, always have sagittal crests as adults. On the other hand, in $H$. sapiens neither the size of the masticatory apparatus nor cranial capacity closely correlates with either body size or with each other for the species as a whole. The variation in the masticatory requirements of different diets has led to extensive differences in the development of the masticatory apparatus among numerous populations (Hunt, '59; Scott, '57; Waugh, '37; Friel, '26). While variation within each population seems to have some dependence on body size, the variation between them does not. If cranial capacity is used as a measure of the amount of area available for the attachment of $m$. temporalis, then this area also is poorly related to body size, (Tobias, '70) if at all. Pakkenberg and Voigt (64), in a study relating brain weight to body size in Danes, report regression coefficients not significantly different from zero when comparing brain and body weight. The regression of brain weight and body height shows some degree of dependence. How little dependence is indicated by Schreider ('66) who reports correlations of brain weight and body height for 224 male and 111 female samples as 0.26 and 0.31 respectively. Thus, this relationship is not particularly close. The combination of two factors, each poorly if at all related to body size, suggests the prediction that the distance between the temporal lines for a mixed $H$. sapiens sample should be more or less independent of either body size or cranial size. Evidence supporting this contention can easily be compiled from data given by Riesenfeld ('55).

Chimpanzees provide a third model of cresting. The relations of $m$. temporalis and the masticatory apparatus is much like that of gorillas. However, because absolute body size is much less, and the range is not as extensive, cresting depends more on individual variations in the relation of cranial size and temporalis size. This contrasts with gorillas where both variation in size, and absolute size itself, is so great that allometric changes in the relation of the masticatory apparatus to cranial size actually can hide individual variations in this relation. That is, the allometric contribution, in accounting for a great deal of the observed variation, obscures the contribution of individual variation in cranial size and the size of the masticatory apparatus separately. In a sample of over 100 chimpanzees in the Hamann-Todd collection, I observed that while sagittal cresting occurred more often on larger than smaller individuals, the pattern was far from uniform. Some cresting occurred in smaller individuals and many of the larger specimens were uncrested. The pattern for gibbons reported by Holloway ('62) appears to be the same.

These considerations give us three possible models which may apply to the australopithecines: great dependence on body size, some dependence on individual variation, and great dependence on individual variation. The key factor is the relative importance of the allometric contribution to the area available for $m$. temporalis attachment.

Robinson ('58: 425) relates variation in australopithecine crest formation to the height of the calvaria and the size of the jaws and teeth. This hypothesis is difficult either to confirm or deny since no South African specimen allows the measurement of both cranial height and summed posterior tooth area, the best functional measure of the masticatory apparatus (Wolpoff, '71b). In fact, cranial height cannot be taken for any South African robust australopithecine! Two gracile specimens with teeth can be measured for cranial height. However, for STS 71 only $\mathrm{M}^{2}$ is measurable, while for MLD $37 / 38$ only $\mathrm{M}^{3}$, so these cannot be directly compared.

It is not possible to relate cresting to body height. Only two South African specimens have related cranial and postcranial skeletal material. For STS 7, the cranial material is a mandible while the TM 1517 cranium is without frontal, parietals, or occipital. 
This leaves only the possibility of trying to relate the position of the temporal lines to the size of the cranium. In the Swartkrans adult sample of four, the only specimen without a sagittal crest is the smallest in comparable cranial dimensions. This seems to fit the gorilla model. The Swartkrans juveniles are more difficult to judge, since SK 54 cannot be aged. Interestingly, SK 54 is a larger calvaria than SK 27, and the temporal lines are closer together. The problem in comparing the ages of these two lies in the fact that while the larger size and more prominent lines of SK 54 argue for it being older, the less developed supraorbital torus could indicate that it is younger. Since both calvarial size and supraorbital development show great variation among the Swartkrans adults, no conclusion can be drawn.

In the gracile sample of seven adults, combining Sterkfontein and Makapansgat, two specimens are likely to have sagittal crests, and the temporal lines meet at breg$\mathrm{ma}$ in a third. One of the probably crested specimens, MLD 1, is larger than all other gracile crania in comparable measures. STS 71 , the specimen for which the lines meet at bregma, is larger than the remaining graciles in occipital measurements, excepting the biasterionic breadth of MLD 1 and MLD $37 / 38$. On the other hand, it is at the low end of the range in most dimensions taken on the parietals and frontal. This suggests that it is the relatively small calvaria rather than a relatively large masticatory apparatus which results in the high temporal lines. For STS 17, the second specimen that probably had a sagittal crest, no calvarial measurements are possible. Table 3 compares facial measurements with STS 5 and 71 . STS 17 is smaller than these in most dimensions, and in fact is one of the smallest faces at Sterkfontein. Small faces do not necessarily go with small calvariae. For instance, some facial dimensions of STS 71 are greater than those of STS 5. Yet, STS 5 is larger in most calvarial dimensions, and has a greater cranial capacity (Holloway, '70). However, since STS 17 was probably crested, one would expect a very small calvaria to go with the face. STS 71 , with a smaller calvaria than STS 5, has closer temporal lines. The only juvenile specimen for which information is available, STS 1006, has high temporal
TABLE 3

Size comparisons of the STS 17 face with the other Sterkfontein faces on crania with temporal line position information

\begin{tabular}{|c|c|c|c|c|}
\hline & $\begin{array}{c}\text { Outer } \\
\text { orbital } \\
\text { breadth }\end{array}$ & $\begin{array}{l}\text { Upper fa- } \\
\text { cial height }\end{array}$ & $\begin{array}{l}\text { Alveolar } \\
\text { height }\end{array}$ & $\begin{array}{c}\text { Height } \\
\text { from alveo- } \\
\text { lar margin } \\
\text { at } \mathrm{M}^{2} / \mathrm{M}^{3} \text { to } \\
\text { the superi- } \\
\text { or supraor- } \\
\text { bital sur- } \\
\text { face }\end{array}$ \\
\hline & $m m$ & $m m$ & $m m$ & $m m$ \\
\hline STS 17 & 96 I & $66^{2}$ & 23.7 & 84.5 \\
\hline STS 5 & 103 & 73.5 & 32.5 & 91 \\
\hline STS 71 & 931 & 77.0 & 28 & 87 \\
\hline
\end{tabular}

1 Estimated by doubling the midline distance.

2 Position of nasion reconstructed.

lines. Their position on the frontal is already far more medial than the position of the lines in the corresponding area of STS 5. It is possible that the adult would have had a sagittal crest. This possibility is enhanced by the correspondence of the temporal lines in this specimen to a Swartkrans juvenile of similar age, SK 27.

The gracile sample seems to follow the chimpanzee model of cresting. While the largest specimen has a crest, one of the smallest also does. Thus, cresting seems to respond to individual variation in the relationship of cranial and masticatory apparatus size. This presumably relates to the smaller body size of the gracile australopithecines, reducing the allometric component of this relationship. Among the uncrested graciles, there is no apparent pattern of relationship between most measures of cranial size and the height of the temporal lines. The only measure that seems to covary uniformly with the distance between the temporal lines is the lambdaopisthion arc for four specimens. Specimens with greater arcs have closer lines. Interestingly, I have used the lambda-opisthion chord in regression equations to predict successfully cranial capacities in other hominid species (Wolpoff, '71c). In sum, the position of the temporal lines in the gracile sample can best be explained as a combination of allometric size changes and individual variation in the relation of cranial size and the masticatory apparatus.

Comparing the single uncrested adult Swartkrans specimen (SK 80/847) with the gracile sample is of some interest. As tables 1 and 2 indicate, the specimen is on the 
small end of the gracile range in most cranial dimensions. One might expect a mixture of the presence and absence of cresting in small specimens as additional specimens are recovered.

The pattern of australopithecine cresting is somewhat different than that of other hominoids. Robinson ('58) first pointed out that cresting in the australopithecines tended to be anterior, compared with the pongids. Every known crest begins anterior to bregma and in the specimen where the lines only meet, they meet at bregma. The separate lamina of the crest fuses anterior to bregma before the posterior segment fuses. Tobias ('67) reported fusion of the anterior portion of the $\mathrm{OH} 5$ crest, and the same anterior fusion occurs for ER 406. In SK 48 and 46 the entire preserved crest is fused, but in SK 49, dentally older than $\mathrm{OH} 5$, the anterior segment is not fused. These data suggest that the anterior portion of the crest forms first, but also indicates variation in the age of crest formation.

Because of the increased anterior component of $m$. temporalis, the temporal crest parallels the superior orbital margin to a far more medial position than is usually the case in pongids (Tobias, ' 67 ). I have observed that both the origin of the crest and the closest approach of the temporal lines in the uncrested specimens are uniformly anterior. Jolly ( $70: 13)$ suggests that the more anterior $m$. temporalis attachment acts to bring the action of the muscle "almost parallel to that of the masseters." Actually, in the larger specimens the action of the masseters themselves is brought forward by a very anterior position for the zygomatic process of the maxilla. I believe the main function of the anterior masseter attachment and the strongly developed anterior component of $m$. temporalis is to bring the resultant of these with the posterior fibers of $m$. temporalis, when it is used contralaterally, through the anterior area of the molar row. This would maximize the power available to the cheek teeth, and is likely adaptive to a dietary regime including hard objects. Consequently in the larger specimens, teeth in close proximity to the anterior portion of the molar row, such as the fourth premolar, tend to be heavily molarized.
In sum, the unique features in australopithecine cresting are part of a total morphological pattern adapted to generating powerful horizontal forces through the entire molar-premolar row during mastication. The occurrence of this morphology suggests that hard objects made up an important part of the australopithecine diet.

\section{CONCLUSION}

Sagittal cresting occurs in both gracile and robust South African australopithecine samples. The frequency difference between these samples, if significant, probably relates to the generally larger body size of the robusts. The pattern of australopithecine cresting indicates a larger anterior temporalis component which, in conjunction with the anterior position of the zygomatic process, is part of a total morphological pattern of adaptation to a diet including foods which require powerful crushing during mastication.

\section{ACKNOWLEDGMENTS}

I am deeply indebted to C. K. Brain and E. Voigt of the Transvaal Museum, P. V. Tobias and A. R. Hughes of the Department of Anatomy, University of the Witwatersrand, and M. D. Leakey, M. D. M. Leakey, and R. E. F. Leakey of the National Museums of Kenya, Centre for Prehistory and Palaeontology, for permission to examine the fossil hominid material in their possessions, and for the help and encouragement given to me during my visit. I am grateful to the Cleveland Museum of Natural History for permission to study the HamannTodd collection.

\section{LITERATURE CITED}

Brain, C. K. 1970 New finds at the Swartkrans australopithecine site. Nature, 225: 1112-1119.

Broom, R., and J. T. Robinson 1952 Swartkrans ape-man. Transvaal Mus. (Pretoria) Mem., 6.

Broom, R., J. T. Robinson and G. W. H. Schepers 1950 Sterkfontein ape-man Plesianthropus. Transvaal Mus. (Pretoria) Mem., 4.

Broom, R., and G. W. H. Schepers 1946 The South African fossil ape-men: The Australopithecinae. Transvaal Mus. (Pretoria) Mem., 2.

Clarke, R. J., F. C. Howell and C. K. Brain 1970 More evidence of an advanced hominid at Swartkrans. Nature, 225: 1219-1222.

Dart, R. A. 1948 The Makapansgat proto-human Australopithecus prometheus. Am. J. Phys. Anthrop., 6: 259-281. 
1962 The Makapansgat pink breccia australopithecine skull. Am. J. Phys. Anthrop., 20: 119-126.

Friel, S. 1926 An investigation in to the relation of function and form. Brit. Dent. J., 47:353-379.

Holloway, R. L. 1962 A note on sagittal cresting. Am. J. Phys. Anthrop., 20: 527-530.

1970 Australopithecine endocast (Taung specimen, 1924): A new volume determination. Sci., 168: 966-968.

1972 New australopithecine endocast, SK 1585, from Swartkrans, South Africa. Am. J. Phys. Anthrop., 37: 173-186.

Hunt, E. E. 1959 The continuing evolution of modern man. Cold Spring Harbor Symp. Quant. Biol., 24: 245-254.

Huxley, J. S. 1932 Problems of Relative Growth. Methuen, London.

Jolly, C. J. 1970 The seed-eaters: A new model of hominid differentiation based on a baboon analogy. Man, 5: 1-26.

Leakey, R. E. F., J. M. Mungai and A. C. Walker 1971 New australopithecines from East Rudolf, Kenya. Am. J. Phys. Anthrop., 35 : 175-1 86.

1972 New australopithecines from East Rudolf, Kenya (II). Am. J. Phys. Anthrop., 36: 235-252.

Pakkenberg, H., and J. Voigt 1964 Brain weight of the Danes. Acta Anat., 56: 297-307.

Riesenfeld, A. 1955 The variability of the temporal lines, its causes and effects. Am. J. Phys. Anthrop, 13: 599-620.
Robinson, J. T. 1958 Cranial cresting patterns and their significance in the Hominoidea. Am. J. Phys. Anthrop., 16:397-428.

Schreider, E, 1966 Brain weight correlations calculated from original results of Paul Broca. Am. J. Phys. Anthrop., 25: 153-158.

Scott, J. H. 1954 The growth and function of the muscles of mastication in relation to the devel opment of the facial skeleton and of the denti tion. Am. J. Orthodont., 40: 429-449.

1957 Muscle growth and function in rela tion to skeletal morphology. Am. J. Phys. An throp., 15: 197-234.

Tobias, P. V. 1967 Olduvai Gorge, Volume II The Cranium and Maxillary Dentition of Australopithecus (Zinjanthropus) boisei. Cambridge University Press, London.

1970 Brain-size, grey matter, and race - fact or fiction? Am. J. Phys. Anthrop., 32: 3-26.

Waugh, L. M. 1937 Influence of diet on the jaws and face of the American Eskimo. J. Am. Dent. Assn., 24: 1640-1647.

Wolpoff, M. H. 1971 a Is the new composite cranium from Swartkrans a small robust australo pithecine? Nature, 230: 398-401.

$1971 \mathrm{~b}$ A functional measure of tooth size Southw. J. Anthrop., 27: 279-286.

$1971 \mathrm{c}$ Vertesszöllös and the presapiens theory. Am. J. Phys. Anthrop., 35: 209-216.

Zuckerman, S. 1966 Myths and methods in Anatomy. J. Roy. Col. Surg. Edinb., 11:87-114.

Note added in proof: Recent experimental work indicates an additional factor that should be considered in the analysis of australopithecine cresting. Biomechanical analysis of the magnitude and direction of temporalis, pterygoid, and masseter muscles in modern man accurately predict measured tooth load, under the assumption that the joint reaction force in the mandibular fossa is minimized during molar loading. The force diagram leads to a set of three simultaneous equations which allow solution for the magnitude of temporalis and masseter force given the directions of these muscles and the magnitude of the tooth load. In the australopithecines, tooth load can be estimated using the proportional difference in summed posterior area compared with modern man. The average direction of temporalis is minimally the same as modern man, although I have suggested this component should be somewhat more anterior. The masseter direction can be estimated from the position of the zygomatic process of the maxilla. Four specimens were analyzed using these assumptions: STS 5 articulated with STS 52 , SK 80 articulated with SK 15, SK 52 articulated with SK 23 , and $\mathrm{OH} 5$ articulated with the mandible reconstructed by R. Clarke. In modern man, the average ratio of temporalis to masseter force magnitude during molar loading is 1.1. In these australopithecine specimens the ratios were $1.8,2.0,2.1,2.2$ respectively. This variation stems from the more anterior placement of masseter, resulting in a greater posterior component of temporalis. Thus in the specimen with the most anterior masseter attachment, the expected force in masseter is about double that in modern man, while the temporalis force is about four times that of modern man. If the line of action for temporalis is more anteriorly directed, the expected posterior component will be even greater. In any event, the mag- 
nitude of temporalis varies with the flexion of the masseter angle. All other things being equal, specimens with a more anterior masseter attachment can be expected to have higher temporal lines and, if the cranium is small enough, a crest. Anterior temporalis development relates more closely to the force through the tooth row while posterior development is a function of both lateral force and the flexion of the masseter angle. 